\title{
Рынок неохлаждаемых микроболометров для ИК-камер: тенденции и перспективы
}

\author{
Н. Кульчицкий, д. т. н. ${ }^{1}$, А. Наумов ${ }^{2}$, В. Старцев ${ }^{3}$
}

УДК 621.315.592 | ВАК 05.11.07

\begin{abstract}
Развитие рынка инфракрасных (ИК) тепловизионных приборов с момента их возникновения было обусловлено прежде всего применением этих устройств в военной технике. Сегодня спрос на тепловизионные камеры наблюдения в военном секторе по-прежнему обеспечивает некоторый рост рынка. Но парадигма развития изменилась - основное увеличение объема выпускаемой продукции связано с гражданской термографией, охранным и пожарным наблюдением, персональными системами ночного видения (PVS) и локальными рынками безопасности (муниципальными, частными и пр.). Растущий спрос на тепловизионные ИК-системы, продиктованный как военным, так и гражданским применением, в свою очередь, вызовет рост мирового рынка тепловых фотоприемных устройств в ближайшие годы.
\end{abstract}

\section{РАЗВИТИЕ РЫНКА ИК-КАМЕР}

Устройства с использованием тепловизоров позволяют осуществлять наблюдение в условиях плохой видимости, обнаруживать скрытые объекты, вести целеуказание. Они используются в системах технического зрения, для обеспечения безопасности авиа- и судовождения, контроля и охраны любых объектов. МЧС применяет такие устройства при спасательных работах во время ликвидации пожаров, для определения наиболее опасных участков с высокой температурой и пр.

Тепловизионные приборы можно разделить на два класса - устройства на основе фотонных (охлаждаемых и неохлаждаемых) детекторов и на базе тепловых (неохлаждаемых) детекторов (микроболометров). Фотонные приемники излучения обеспечивают преобразование падающего потока фотонов в электрический сигнал благодаря непосредственному взаимодействию фотонов с электронной подсистемой материала приемника. Основные материалы для создания фотонных приемников тройное полупроводниковое соединение кадмий-ртутьтеллур (HgCdTe) для спектральных диапазонов 1-2,5 мкм, 3-5 мкм и 8-14 мкм, двойное полупроводниковое соединение антимонид индия (InSb) для спектрального диапазона 3-5 мкм, тройное полупроводниковое соединение

Московский технологический университет (МИРЭА), профессор; Московский государственный университет им. М.В.Ломоносова; Государственный научный центр РФ; АО «НПО «ОРИОН» (Москва), n.kulchitsky@gmail.com.

АО «ОКБ "Астрон», ст. научн. сотр. (Лыткарино, МО).

АО «ОКБ «Астрон», вед. научн. сотр. (Лыткарино, МО). индий-галлий-арсенид (InGaAs) для спектрального диапазона 0,4-2,3 мкм.

Неохлаждаемый тепловой детектор (болометр) представляет собой резистор, изготовленный из материала с очень малой теплоемкостью и большим температурным коэффициентом сопротивления. В этом случае поглощенное им излучение значительно изменяет его сопротивление. Принцип действия болометра основан на

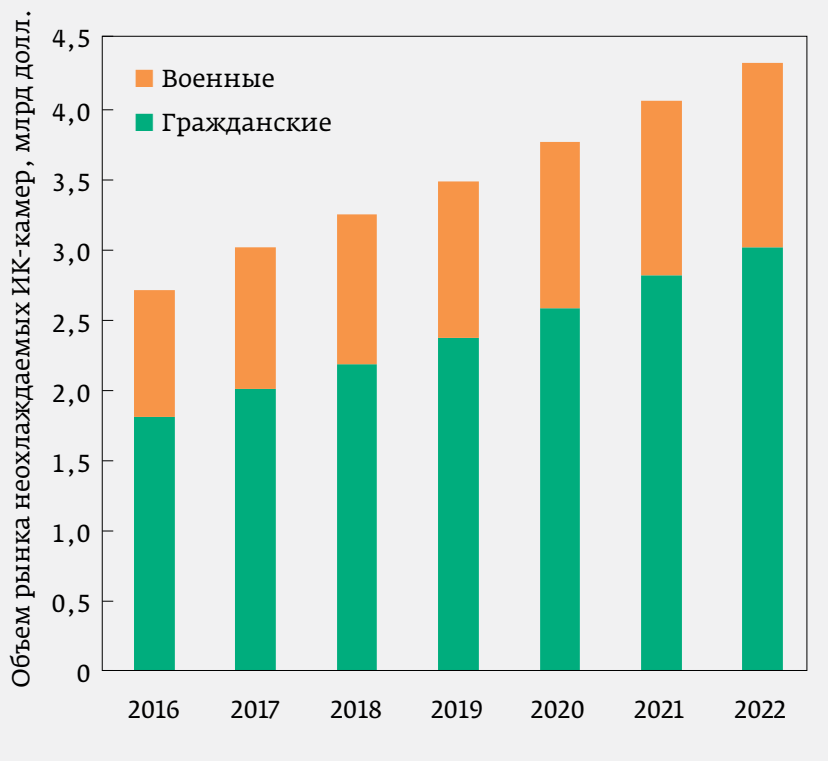

Рис. 1. Развитие рынка неохлаждаемых ИК-камер (2016-2022 гг.) в млрд долл. Источник: Yole Development 


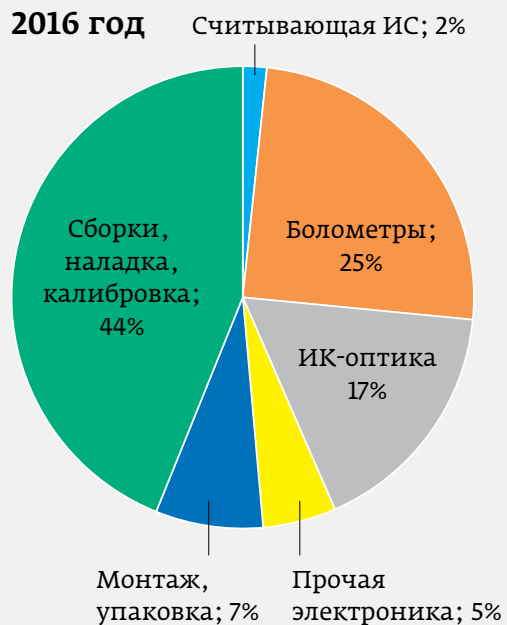

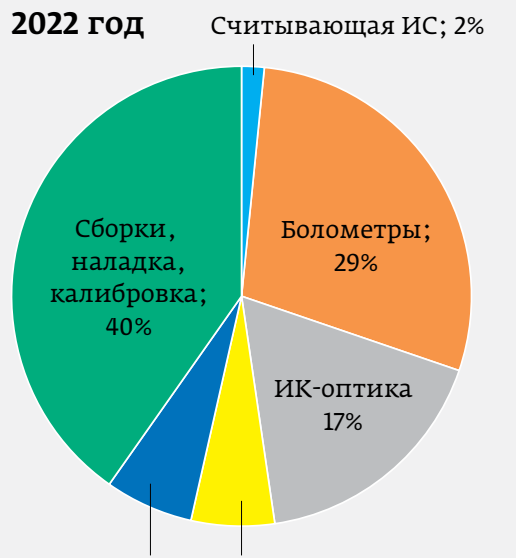

Монтаж, Прочая упаковка; 6\% электроника; 6\%

Рис. 2. Структура рынка ИК-камер по составляющим элементам и прогноз до 2022 года в процентах. Источник: Yole Development

изменении сопротивления, как в фоторезисторе, но основной механизм детектирования другой. В болометре падающее излучение нагревает материал, что, в свою очередь, приводит к изменению сопротивления. Прямого взаимодействия фотонов с электронами материала в данном случае нет [1, 2].

Охлаждаемые фотонные сенсоры имеют температурную чувствительность, равную минимальной эквивалентной шуму разности температур (Noise Equivalent Temperature Difference - NETD) 10-20 мК. Обнаружительная способность охлаждаемых приемников примерно на два порядка выше, чем у неохлаждаемых. Но сегмент потребителей приборов на микроболометрах более широк из-за низкой цены.

В 2017-2018 годах ежегодно продавалось по 900-1200 тыс. шт. неохлаждаемых ИК-камер на сумму 2,7-3,3 млрд долл. По прогнозам, общий объем рынка этих устройств к2022 году превысит 4 млрд долл. в финансовом исчислении и более 1,7 млн шт. в натуральном. При этом их применение в военной технике будет увеличиваться на 5,6\% в год, а в гражданской сфере - на 8,8\% (рис. 1).

В начале 1990 годов успехи в создании тепловизоров коммерческого применения привели к замене систем с механическим сканированием недорогими камерами прямого обзора на основе неохлаждаемых матриц фокальной плоскости (МФП). Сегодня используется третье поколение фотоприемных устройств - матричные фотоприемные устройства (ФПу) форматом более мегапикселя, которые отличаются расширенными функциональными возможностями (двух- и многоспектральные, сверхмалый размер пикселя и т. п.) [1, 2]. Доля МФП в себестоимости ИК-камер составляет 25-30\% (рис. 2).

\section{ТЕНДЕНЦИИ РАЗВИТИЯ КОНСТРУКЦИИ МИКРОБОЛОМЕТРОВ}

За последние два десятилетия достигнут значительный прогресс в создании неохлаждаемых тепловых детекторов инфракрасного диапазона, которые по пороговым характеристикам приблизились к фотонным детекторам при значительно меньшей стоимости [2-4]

Излучение регистрируется при накоплении в объеме приемника тепла от воздействия энергии излучения за время кадра. Для этого чувствительный элемент максимально теплоизолируется от подложки, что достигается благодаря технологии MEMS, которая базируется на глубоком и сухом травлении кремния с применением "жертвенных" (которые потом удаляются) слоев.

Различают пять типов болометров: металлические, термисторные, полупроводниковые, композитные и сверхпроводящие. Для изготовления металлических болометров обычно используют никель, висмут, платину или сурьму, потому что эти металлы отличаются долговременной стабильностью параметров. Термисторные болометры изготавливаются путем синтеза смеси различных полупроводниковых оксидов с более высоким температурным коэффициентом сопротивления, чем у металлов (2-4\% на градус Цельсия). Полупроводниковые болометры чаще всего выпускаются из легированного галлием и одновременно компенсированного индием германия. Чувствительность этих приемников близка к теоретическому пределу в интервале длин волн 5-100 мкм. В таком германии (типичные концентрации галлия порядка $10^{16} \mathrm{~cm}^{-3}$ и концентрация In примерно $10^{15} \mathrm{~cm}^{-3}$ ) поглощенная энергия быстро передается кристаллической решетке, повышая температуру образца. Композитный или составной болометр состоит из трех частей: поглотителя излучения, подложки, определяющей рабочую площадь прибора, и датчика температуры. Пятый тип болометров - сверхпроводящие, работающие вблизи точки перехода в сверхпроводящее состояние, где температурные изменения сопротивления чрезвычайно велики.

В производстве микроболометров наиболее широко используются такие материалы, как диоксид ванадия $\mathrm{VO}_{x}$ и легированный аморфный гидрированный кремний a-Si : H

Ванадий - металл переменной валентности - образует несколько оксидов. Изменения удельного 
Считывающая интегральная схема

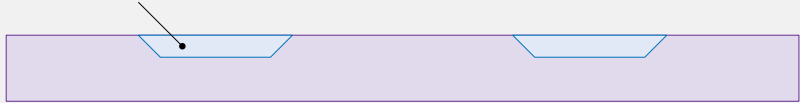

1.

«Жертвенный» слой
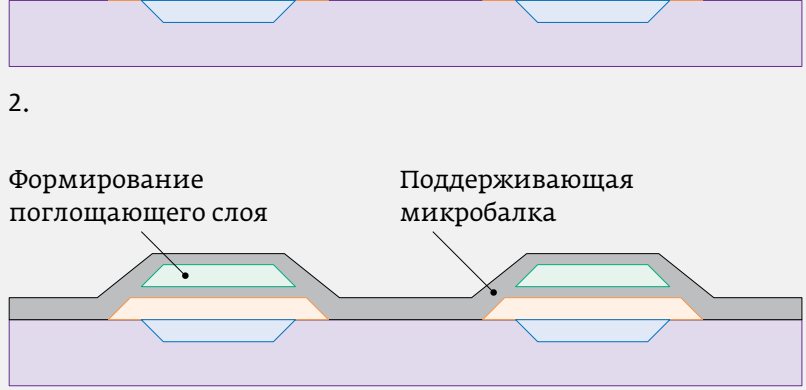

3.

Полость

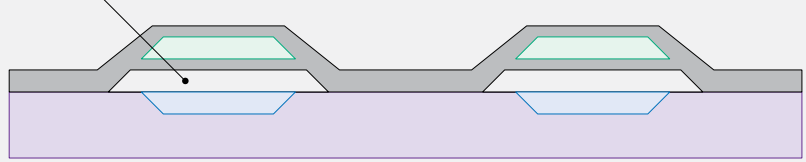

4.

Рис. 3. Основные этапы производства микроболометров

сопротивления и оптических свойств пленок VO сильно зависят от условий изготовления материала, кристаллической структуры и стехиометрии. Важнейшая характеристика $\mathrm{VO}_{x}$ - его высокий отрицательный температурный коэффициент сопротивления (ТKC) при

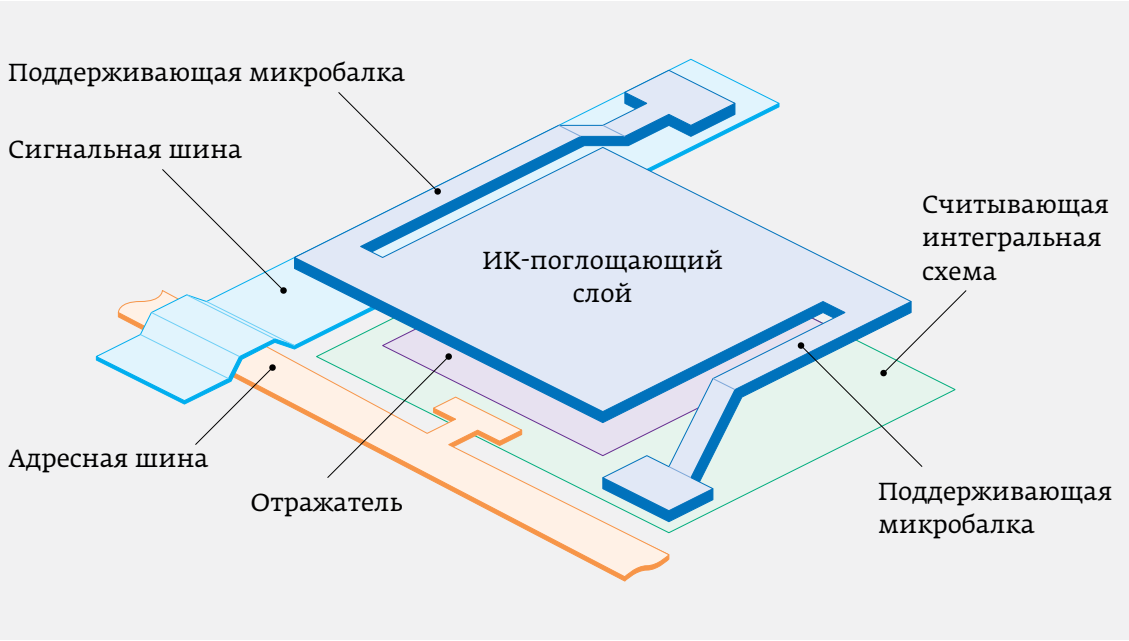

Рис. 4. Конструкции чувствительных элементов тепловых приемников (чувствительный элемент в форме микромостика)

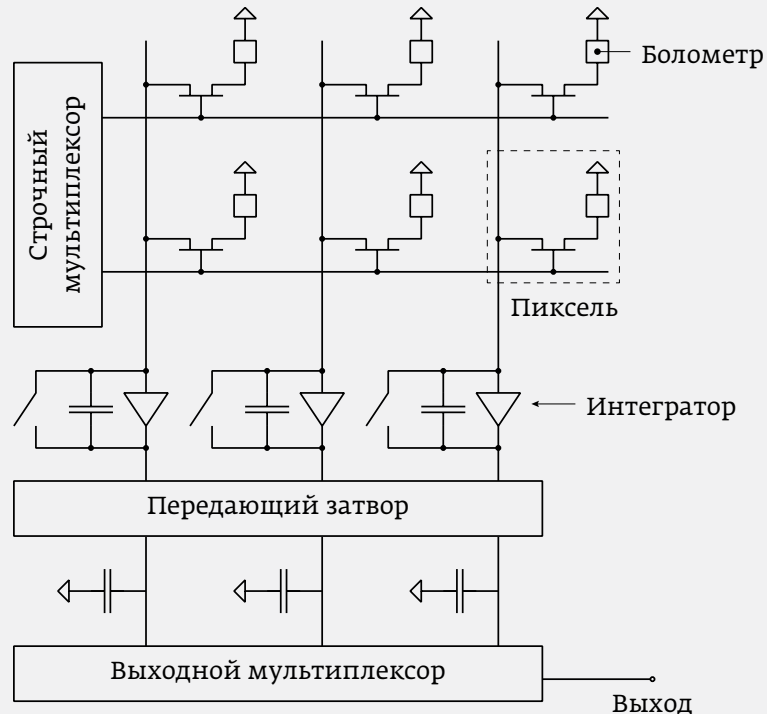

Рис. 5. Пример построения считывающей схемы микроболометра

температурах, близких к комнатным (более 4\% на градус Цельсия).

Болометры на основе a-Si : Н отличаются высоким сопротивлением, но этот материал нестабилен при тепловых обработках и действии ультрафиолетового облучения. Основные этапы производства микроболометров представлены на рис. 3

На поверхности созданных таким путем мембранных конструкций толщиной менее 1 мкм, удерживаемых над подложкой на расстоянии 2 мкм с помощью пары микробалок (поддерживающих консолей), размещается фоточувствительный элемент - тонкопленочная структура (рис. 4). Такие болометры - основной тип детекторов для создания неохлаждаемых и относительно недорогих МФП на основе микроболометров. МФП представляет собой микросхему, объединяющую на одном кристалле матрицу из термочувствительных элементов (пикселей) и схему обработки сигналов, преобразующую изменения сопротивления в выходное напряжение и компенсирующую фоновое излучение (рис. 5). Сопротивление преобразуется в пропорциональный ток с помощью схемы с общим затвором на п-канальном Моптранзисторе. Для компенсации 


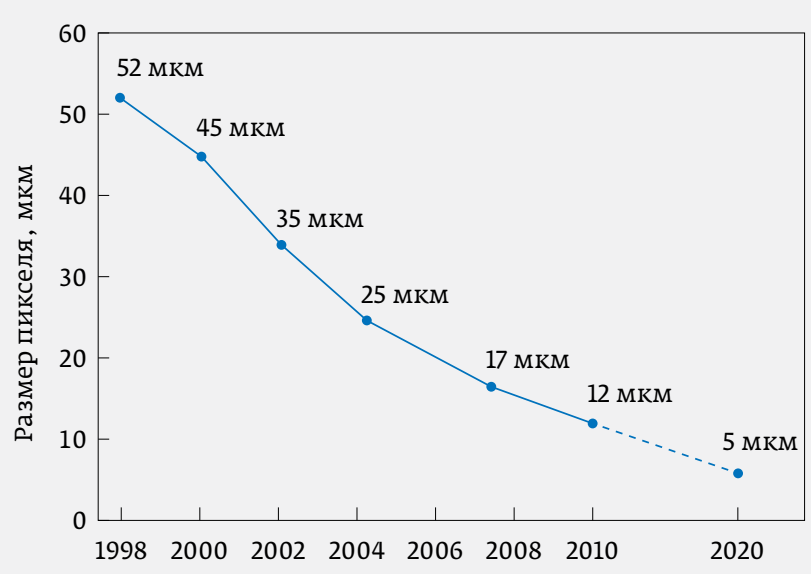

Рис. 6. Динамика снижения размера пикселя для неохлаждаемых микроболометров и прогноз до 2020 года

неинформативной составляющей используется комплементарный каскад - схема с общим затвором на р-канальном МОП-транзисторе.

Стоимость МФП на основе болометров при условии промышленного производства на два порядка меньше, чем стоимость матриц на основе HgCdTe, InSb, при этом типичные значения NETD (температурная чувствительность, равная минимальной эквивалентной шуму разности температур, Noise Equivalent Temperature Difference) для болометрических матриц составляет 50-100 мК (для МФП на основе HgCdTе типичные значения порядка 10 мК). Важнейшее преимущество болометрических инфракрасных детекторов - возможность работы без охлаждения (при температурах около 300 K), в то время как большая часть фотонных детекторов функционирует при криогенных температурах (обычно не менее $77 \mathrm{~K}$ ).

Благодаря перечисленным преимуществам инфракрасные болометрические детекторы в последние годы активно разрабатываются и производятся. В настоящее время для создания тепловых формирователей изображения наиболее широко используются оксид ванадия и легированный a-Si : H, хотя создание приборов на основе этих материалов сопряжено с некоторыми проблемами. Оксид ванадия VО, отличается высокими значениями температурного коэффициента сопротивления (ТКС равно 2-3\%), на основе этого материала созданы матрицы форматом 2048×1536 с размером пикселя 17 мкм [4-6]. Однако оксид ванадия - нестандартный материал для КМОП-технологии, получение оксида ванадия в виде тонких пленок является сложным для управления процессом из-за узкого диапазона технологических параметров, обеспечивающих стабильность и оптимальность характеристик оксида. Кроме того, из-за наличия гистерезиса возникают проблемы при построении тепловых изображений горячих объектов, а теплопроводность таких пленок на порядок больше, чем значения этого параметра для полупроводников (обычно 0,05 Вт / смК). Для болометров на основе a-Si : H характерно высокое сопротивление, но этот материал нестабилен при тепловых обработках и действии ультрафиолетового облучения. Стабильная и метастабильная фазы данного материала разделены потенциальными барьерами, что препятствует формированию равновесного состояния.

В настоящее время основное внимание разработчики уделяют решению технологических проблем совместимости процесса изготовления болометрических матриц с КМОП-технологией, а также оптимизации сопротивления материала, ТКС, тепловой проводимости и других характеристик прибора. В ряде работ рассмотрены возможности использования при создании болометров на базе аморфного соединения $\mathrm{Ge}_{x} \mathrm{Si}_{1-x} \mathrm{O}_{\text {y, }}$ а также материалов с потенциальными ямами на основе n-Sі в подложке из p-Si. Металлы Pt, Ni, используемые для металлических болометров, совместимы с КМОП-технологией, но отличаются низкими значениями ТКС, а болометры на основе сверхпроводящих пленок требуют значительного охлаждения, что существенно повышает стоимость приборов.

Болометрам на основе карбида кремния SiC свойственны высокие значения ТКС (4-6\%), но для стабилизации свойств материала требуется отжиг при температурах около $1000^{\circ} \mathrm{C}$, что несовместимо с КМОП-технологией $[6,9]$. С 2016 года в США и в России ведутся

\begin{tabular}{|l|l|}
\hline $64,20 \%$ & FLIR \\
\hline $16,70 \%$ & Ulis \\
\hline $4,50 \%$ & DRS \\
\hline $1,20 \%$ & L3Technologies \\
\hline $3,40 \%$ & SEEK \\
\hline $2,70 \%$ & ВAE \\
\hline $2,20 \%$ & Raytheon \\
\hline $1,50 \%$ & Dali \\
\hline $1,10 \%$ & SCD \\
\hline $2,50 \%$ & Прочие \\
\hline
\end{tabular}

Рис. 7. Производители неохлаждаемых микроболометров. Источник: Yole Development 


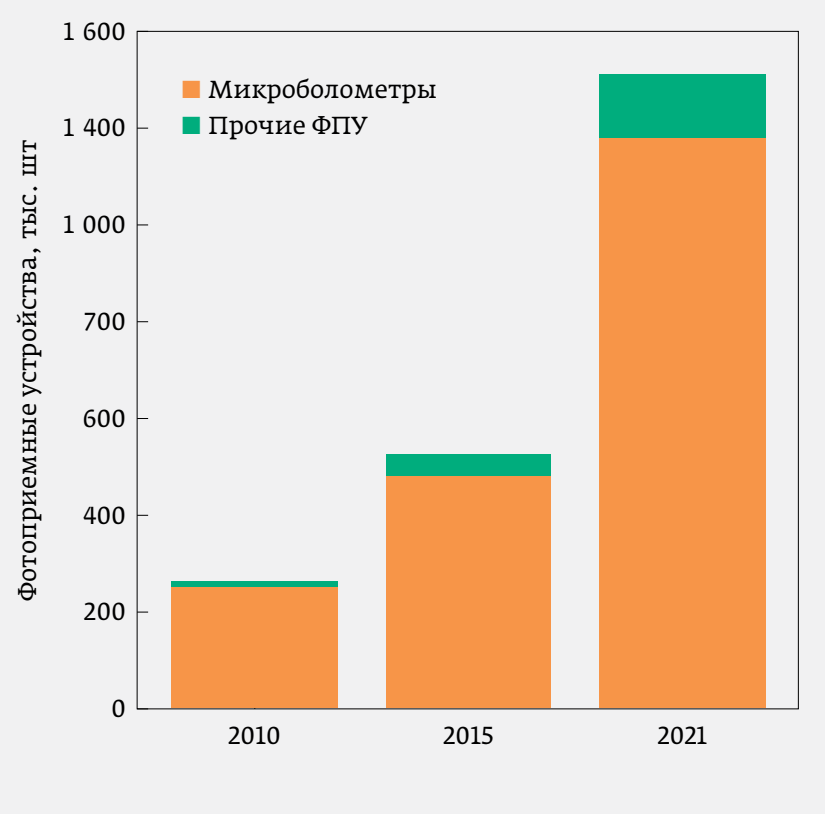

Рис. 8. Прогноз развития производства фотоприемных устройств. Источник: Yole Development

работы по созданию прототипа болометра на основе графена [7].

Другое направление развития мировой и отечественной фотоэлектроники в области МФПУ в ближайшей перспективе - создание матричных массивов фоточувствительных элементов с уменьшенным до 5 мкм шагом элементов (рис. 6), обеспечивающих формирование многопиксельных матриц с низкой дефектностью, а также их гибридизацию с кремниевыми считывающими схемами [10].

\section{РЫНОК МИКРОБОЛОМЕТРОВ (МБ)}

Ведущие производители микроболометров находятся в США: L3, BAE, DRS, FLIR, Raytheon. В Европе лидирующие позиции занимает французская компания Ulis, в Израиле - SCD, в Японии - NEC. Следует отметить разработки и выпуск микроболометров в сравнительно небольших количествах в Китае компанией Dali (pис. 7).

По мнению аналитиков агентства Yole, тепловые детекторы, работающие на принципах микроболометров, останутся основным сектором среди МФПУ, а объемы их выпуска значительно вырастут в ближайшие годы (рис. 8).

На мировом рынке широко представлены неохлаждаемые ФПу, серийно выпускаемые мировыми производителями (табл. 1) [8].

\section{$\bullet$ \\ Рис. 9. \\ ФПУ \\ АСТРОН-38417-1 \\ и АСТРОН-64017-1}

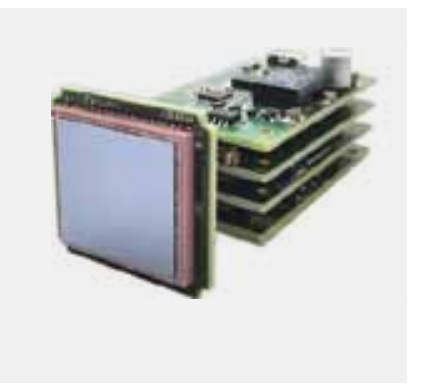

Рис. 10.

Модуль АСТРОН-640M17

\section{СИТУАЦИЯ В СССР И РОССИИ}

Первые попытки создания МБ-матриц были предприняты в 1994-1995 годах в НПО «Орион» (Москва) [1, 10]. В начале 2000-х годов предприятие приступило к разработкам приборов формата $320 \times 240$ на базе оксида ванадия на подложке из нитрида кремния. Однако развивающийся рынок гражданских и охранных применений требовал большого количества МБ. До недавних пор отечественная техника обеспечивалась тепловизионными системами в формате закупки либо совместного производства с иностранными соисполнителями. Необходимость разработки и серийного выпуска отечественных неохлаждаемых МБ стала особенно актуальной после запрета их поставок из-за рубежа. В 2016 году на предприятии АО «ОКБ «Астрон» было освоено производство ФПУ с чувствительностью до 40 мК: АСТРОН-38425-1 и АСТРОН-64025-1 с размером чувствительных элементов матрицы 25 и 17 мкм. ФПУ изготовлено на основе матрицы микроболометров с электронной подсистемой считывания, упакованной в керамический корпус, отличается высокой чувствительностью, низким энергопотреблением и малым весом. ФПУ снабжено массивом микроболометров в виде двумерной матрицы элементарных

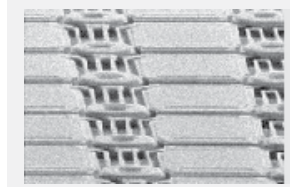

a)

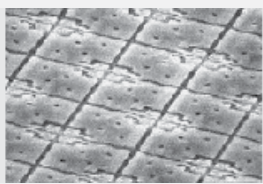

б)

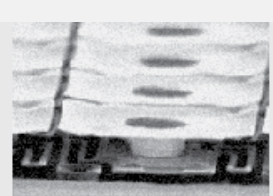

B)

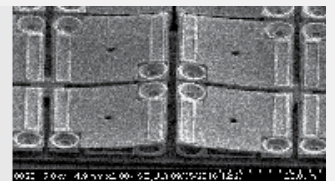

г)
Рис. 11. Топология микроболометрических детекторов разных производителей: BAE на $\mathrm{VO}_{\mathrm{x}}(\mathrm{a})$, Ulis на a-Si (б), DRS на VO 
Сравнительные характеристики неохлаждаемых ФПУ различных производителей

\begin{tabular}{|c|c|c|c|c|}
\hline Компания & Материал болометра & Формат матрицы & $\begin{array}{r}\text { Размер пикселя, } \\
\text { мкм }\end{array}$ & $\begin{array}{r}\text { Значение NEDT } \\
(\mathrm{mK})\end{array}$ \\
\hline \multirow[t]{2}{*}{ L-3 (США) } & $\mathrm{a}-\mathrm{Si}$ & $160 \times 120 ; 640 \times 480$ & 30 & 50 \\
\hline & a-Si/a-SiGe & $320 \times 240 ; 1024 \times 768$ & 17 & $30-50$ \\
\hline \multirow[t]{2}{*}{ BAE (США) } & $\mathrm{VO}_{\mathrm{x}}$ & $640 \times 480$ & 12 & $<50$ \\
\hline & $\mathrm{VO}_{\mathrm{x}}$ & $1024 \times 768$ & 17 & $<50$ \\
\hline \multirow[t]{2}{*}{ DRS (СШA) } & $\mathrm{VO}_{\mathrm{x}}$ & $320 \times 240$ & 25,17 & $<40$ \\
\hline & $\mathrm{VO}_{\mathrm{x}}$ & $640 \times 480 ; 1024 \times 768$ & 17 & $<40$ \\
\hline \multirow[t]{3}{*}{ Raytheon (СШA) } & $\mathrm{VO}_{\mathrm{x}}$ & $320 \times 240 ; 640 \times 480$ & 25 & $30-40$ \\
\hline & $\mathrm{VO}_{\mathrm{x}}$ & $320 \times 240 ; 640 \times 480$ & 17 & 50 \\
\hline & $\mathrm{VO}_{\mathrm{x}}$ & $1024 \times 480 ; 2048 \times 1536$ & 17 & 50 \\
\hline \multirow{5}{*}{ ULIS (Франция) } & $\mathrm{a}-\mathrm{Si}$ & $80 \times 80$ & 34 & $<100$ \\
\hline & $\mathrm{a}-\mathrm{Si}$ & $160 \times 120$ & 25 & $<60$ \\
\hline & $\mathrm{a}-\mathrm{Si}$ & $320 \times 240$ & 12 & $<60$ \\
\hline & $\mathrm{a}-\mathrm{Si}$ & $384 \times 240$ & 17 & $<55$ \\
\hline & $\mathrm{a}-\mathrm{Si}$ & $640 \times 480 ; 1024 \times 768$ & 17 & $<50$ \\
\hline \multirow[t]{4}{*}{ SCD (Израиль) } & $\mathrm{VO}_{\mathrm{x}}$ & $384 \times 288$ & 25 & $<20$ \\
\hline & $\mathrm{VO}_{\mathrm{x}}$ & $384 \times 288$ & 25 & $<35$ \\
\hline & $\mathrm{VO}_{\mathrm{x}}$ & $640 \times 480$ & 17 & $<35$ \\
\hline & $\mathrm{VO}_{\mathrm{x}}$ & $1024 \times 768$ & 17 & $<35$ \\
\hline \multirow[t]{2}{*}{ FLIR Systems (США) } & $\mathrm{VO}_{\mathrm{x}}$ & $640 \times 512$ & 17 & $<60$ \\
\hline & $\mathrm{VO}_{\mathrm{x}}$ & $336 \times 256$ & 17 & $<50$ \\
\hline \multirow[t]{2}{*}{ ОКБ «Астрон" (Россия) } & $\mathrm{VO}_{\mathrm{x}}$ & $384 \times 288$ & 17 & $<50$ \\
\hline & $\mathrm{VO}_{\mathrm{x}}$ & $384 \times 288$ & 17 & $<50$ \\
\hline \multirow[t]{4}{*}{ NEC (Япония) } & $\mathrm{VO}_{\mathrm{x}}$ & $320 \times 240$ & 23,5 & $<75$ \\
\hline & $\mathrm{VO}_{\mathrm{x}}$ & $640 \times 480$ & 23,5 & $<75$ \\
\hline & $\mathrm{VO}_{\mathrm{x}}$ & $640 \times 480$ & 12 & 60 \\
\hline & $\mathrm{VO}_{\mathrm{x}}$ & $320 \times 240$ & 23,5 & $\mathrm{NEP}<100 \mathrm{pBT}$ \\
\hline
\end{tabular}


детекторов, расположенных в фокальной плоскости, состоящей из 384 × 288 элементов (ФПУ АСТРОН-38417-1) и $640 \times 480$ (ФПУ АСТРОН-64017-1). Микроболометры выполнены из оксида ванадия по мостиковой схеме. ФПу выдает необработанное изображение в аналоговом формате со скоростью до 60 кадров в секунду. Управление электронной подсистемой ФПУ осуществляется по последовательной шине данных. Размер пикселя составляет 17×17 мкм. ФПУ выполнено в корпусе LCC (Leadless chip Carrier) из вакуумплотной керамики рис. 9 [10]. Пример коммерчески доступного отечественного модуля на основе ФПУ АСТРОН-64017-1 изображен на рис. 10. Топология микроболометрических детекторов разных производителей приведена на рис. $11[8,10]$.

Работы по созданию микроболометрических матриц на основе оксидов ванадия ведутся также в ИФП СО РАН (Новосибирск) $[10,11]$.

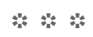

Болометры являются перспективным типом детекторов для создания неохлаждаемых и относительно недорогих МФП. Стоимость МФП на основе неохлаждаемых болометров при условии промышленного производства на два порядка меньше, чем стоимость матриц на основе HgCdTe, InSb. Типичные значения NETD для болометрических матриц варьируются в пределах 50-100 мК. Следует отметить, что тепловая постоянная времени для всех микроболометров достаточно велика и составляет 10 мс.

Основные тенденции развития МБ заключаются в следующем:

- переход на полный формат $(1280 \times 1024)$ и сверхкрупноформатные матрицы $(2048 \times 1536)$;

- повышение функциональных возможностей: двухи многоспектральные МБ;

- повышение уровня технологий неохлаждаемых МБ-матриц (корпусирование на кристалле и т.д.);

- поиск новых принципов детектирования ИК-излучения и новых фоточувствительных материалов (графен, другие 2D-структуры и т. п.)
Отечественные разработчики вносят большой вклад в развитие производства оптических систем инфракрасного диапазона с современными и перспективными фотоприемными устройствами. Это упрощает аппаратуру, снижает ее стоимость, массу, габариты, энергопотребление, повышает надежность. При этом может быть получена чрезвычайно высокая температурная чувствительность, обеспечивающая эффективную работу при обнаружении или распознавании слабоконтрастных или замаскированных объектов. Все это приблизит тепловизионные изображения по информационной емкости к возможностям зрения человека.

\section{ЛИТЕРАТУРА}

1. Rogalski A. Infrared Detectors. CRC-Press Taylor Francis Group. 2-nd ed. London New York. 2011. 876 p.

2. Пономаренко В. П., Филачев А. М. Инфракрасная техника и электронная оптика. Становление научных направления.- М.: Физматкнига, 2016. 417 с.

3. Филачев А. М., Таубкин И. И., Тришенков М. А. Твердотельная фотоэлектроника. Фоторезисторы и фотоприемные устройства. - М.: Физматкнига, 2012. 368 с

4. Tissot J. L., Rothan F., Vedel C., Vilain M., Yon J. J. // Proc. SPIE. 1998. V. 3436. Р. 605-610.

5. Войцеховский А. В., Кульчицкий Н. А., Мельников А. А., Несмелов С. Н. // Нано- и микросистемная техника. 2011. № 2. С. 4-47.

6. Войцеховский А. В., Кульчицкий Н. А., Мельников А. А., Несмелов С. Н. // Материалы международной научно-технической конференции Intermatic-2013. - М., 2013. 4. 1. С. 212-221.

7. Evlashin S., Dyakonov P., Khmelnitsky R., Dagesyan S., Klokov A., Sharkov A., Suetin N. Controllable Laser Reduction of Graphene Oxide Films for Photoelectronic Applications // ACS Appl. Mater. Interfaces 2016. 8. 42. 28880-28887.

8. Rogalski A. Next decade in infrared detectors // Proc. SPIE10433. Electro-Optical and Infrared Systems: Technology and Applications XIV. V.104330L. 9-10 October 2017. doi: $10.1117 / 12.2300779$

9. Демьяненко М. А., Есаев Д.Г., Овсюк В.Н., Фомин Б. И., Асеев А. Л., Князев Б. А., Кулипатов Г.Н., Винокуров Н. А. // Оптический журнал. 2009. Т. 76. № 12. С. 5-11.

10. Кульчицкий Н. А., Наумов А. В., Старцев В.В. Неохлаждаемые микроболометры инфракрасного диапазона: современное состояние и тенденции развития // Нано-и микросистемная техника. 2018. Т. 20. № 10. С. 613-624.

11. Наумов А. В., Старцев В. В. Современные фотоприемные устройства инфракрасного спектра и тенденции развития // Технологии защиты. 2018. № 5. С. 66-70. 